\title{
CONF-8608 $147--2$
}

\section{DISCLAIMER}

This report was prepured us an accounl of work uponsored by an agency of the Uniled States Government. Neither the United States (iovernmert nor uny agency thereof, nor uny of their employees, maken any wurrinly, express of implied, or assumes any legal llablility of responaibility for the accuracy, coimpleteness, or usefulness of uny information, apparatus, product, of prucess dincluned, or reprenents that its use would not infinge privntely owned rights. Keference herein lo uny specific commercial punduct, procens, or service by trade name, trademark. manufacturer, of otherwine dises not necessurily condillute ur inply its enciormenent, reciommendation. or favoring by the United Silltes (jovernment or any agency thereof. The views and opiniuns of authoos expressed herein do not necessarily atnie or reflect those of the Unlted Situten (hovernment or any agency theresi. 
GaAs Photoconductors to Characterize Picosecond Response

in GaAs Integrated Devices and Circuits

Robert B. Hammond, Nicholas G. Paulter, and Alan J. Gibbs

, Los Alamos National Laboratory, Los Alamos, My 87545

\section{Introduction}

Optoelectronic techniques that use femtosecond lasers and promise the precise measurement of transient response in high speed electronic devices and circults have been under study for several years. We have investigated on-wafer electrical-impulse generation and sampling using femtosecond-laser-excited GaAs photoconductors. This approach is applicable to any transmisalon line structure, it is directly integrable, noninvasive, jitter-free, and it is applicable to both microwave and dieital circuits.

We have developed the capability to: a) generate electrical impulses in on-wafer GaAs transnission lines with 3-dB bandwidths in excess of 60 $\mathrm{GHz}$, and b) sample the electrical impulse response of an on-water test structure without jitter and with a 3-dB measurement handwisth of $103 \mathrm{GHz}$ at a noise level of $-67 \mathrm{dBm}$. We have studied dispersion in GaAs on-wafer coplanar-waveguide transmission lines.

\section{Sample Preparation and Experiment}

We prepared on-wafer photoconductor pulse generators and sampling gates in coplanar waveguide transmission lines on 625-um-thick Cr-doped semiinsulating GaAs wijers. Center conductor widths were 67 um and the spacing to the ground planes was $33 \mu \mathrm{m}$. Thls gave a characteristlc impedance of approximately 50 ohms and a cut-off frequency of approximately $100 \mathrm{GHz}$. The photoconductor pulse generators consisted of $25 \mu \mathrm{m}$ gaps in the center conductor. Photoconductor sampling gates were placed at 33 , 400 , and $1200 \mu \mathrm{m}$ distances from the pulsers. The test structures were formed with evaporated AuGe allny, patterned with lift-off photolithography, and annealed at $425^{\circ} \mathrm{C}$ for 2 minutes.

In order to produce photoconductors on GaAs with picosecond response we used lon-beam irradiation to introduce point defects into the semiinsulating substrate. This structural demage produces deep-level trapping sites that reduce carrier-relaxation time in the crystals. The samples were damaged with a dose of $5 \times 10^{14} \mathrm{~cm}^{-2}, 6 \mathrm{MeV}$ He lons. This dose produces a uniform point dofect density of $2 \times 10^{\prime 9} \mathrm{~cm}^{-3}$ in the top $3 \mathrm{microns}$ of the GaAs substrate. Increasing the lon-beam-damage dose above this level caused the materlal to become conductive.

Optoelectronic correlation mensurements wore performed on these test structures $1 \mathrm{dg}$ ing a colliding-pulse modelocked dye laser producing $0.2 \mathrm{pg}$ optlcal pulses at a wavelength of $620 \mathrm{~nm}$, and a repetition rate of 125 MHz.

\section{Experlmental Regults and Analyolo}

Plgure 1 shows a meagurod optoolectronlc correlation from on on-wafor GaAs photoconductor pulBe-generator/sampler palr. A flt to the mrasured correlation using the photoconductor model of D. H. Auston [1] allows us to oeparate the correlation lnto the ampling operture [unction and the 
actual electrical puise shape. In the fit we allowed the carrier relaxation in the pulser and sampler to vary independently. The best fit to the experimental correlation is shown in Fig. 1 , along with the derived sampler aperture function and the electrical pulse shape.

50. $\Omega$ 100.GHz COPLANAR WAVEGUIDE

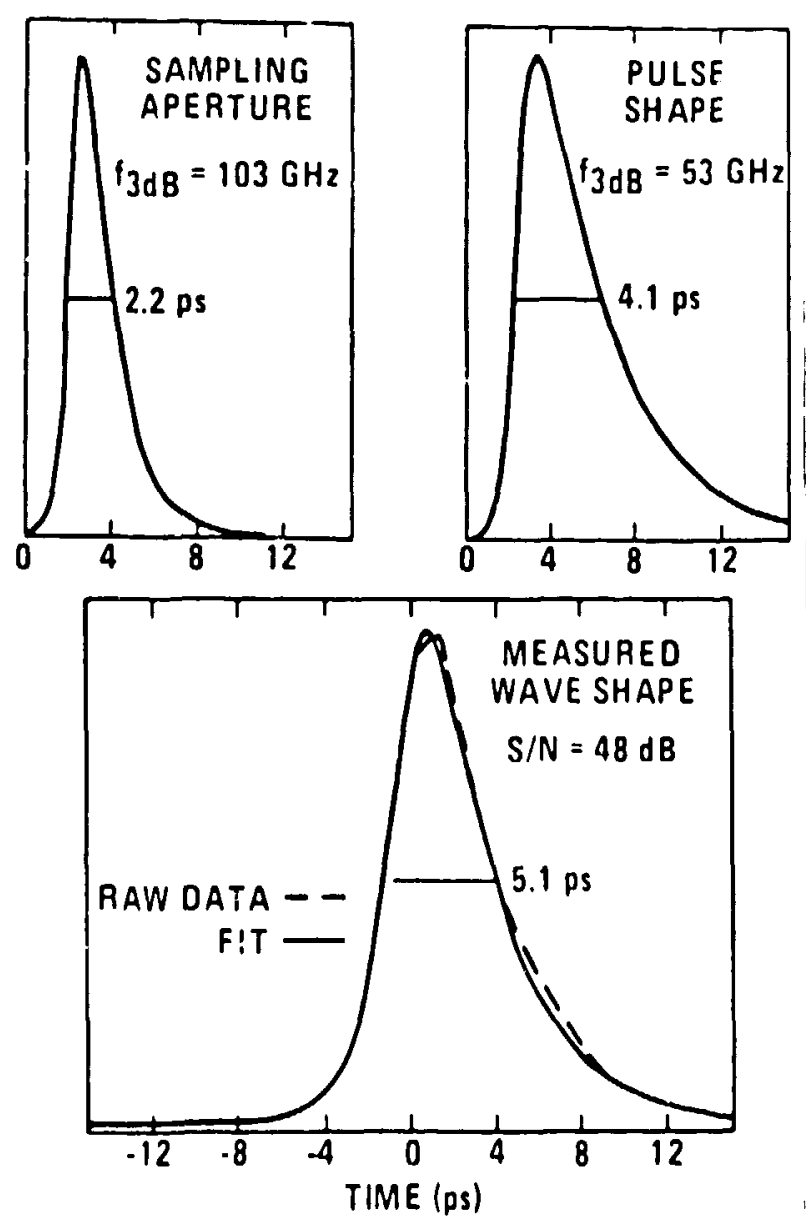

Fig. 1.

Measured optoelectronic correlation between on-wafer GaAs photoconductor pulse generator and sampling gate. The raw data were $f$ it with the model due to D. H. Auston to derive the sampling aperture function and electrical pulse shape. These are also shown

Data from our test structure permitted us to investigate pulse propagation in coplanar-waveguide transmission lines. Figure 2 shows measured correlations taken at distances of 33,400 , and 1200 micron distances from the photoconductor pulse generator. The data indicate that coplanar waveguide has very low dispersion. The data show no degradation in the $3.3 \mathrm{ps}$ risetime of the correlation over the full $1.2 \mathrm{~mm}$ propagation length.

\section{Summary and Conclusion}

In sumnary we have developed on-wafer Gans photoconductors that should permit measurements of tronsient response in GaAs devires and circuits with overall measuroment bandwidths greater than $50 \mathrm{GHz}$ and time resolution of $2.2 \mathrm{ps}$. Because of the absence of jitter in these alectrical measurements it should be possible to characterlze integratod GaAs devices and circults at frequencies up to hundreds of $\mathrm{GHz}$. Also we have shown that coplanar waveguide is a vory low dispersion, scalable. all-planar trangmission line that is very attractive for these li ime-domain measurements. 

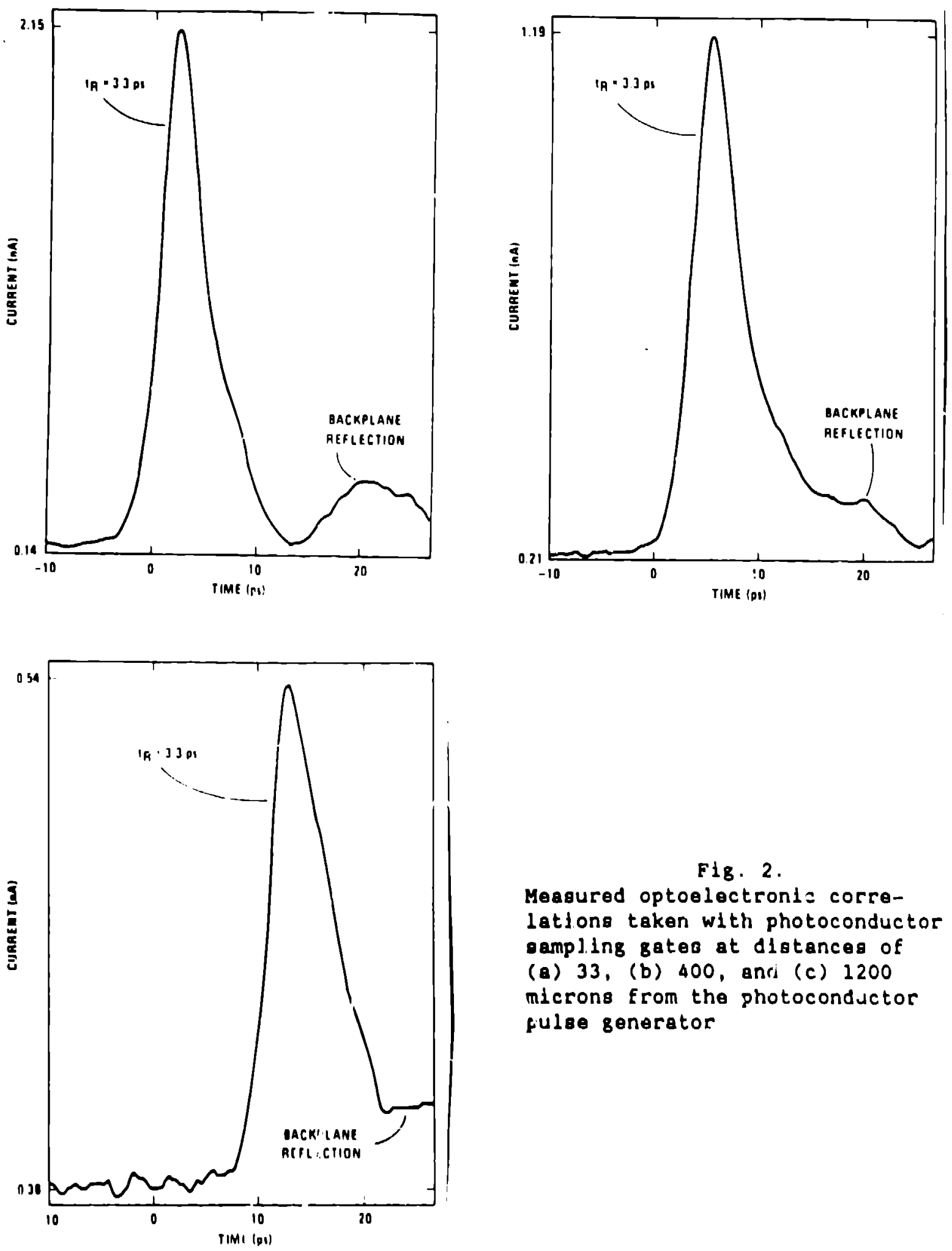

Fig. 2.

Meagured optoelectronis correlatjons taken with photoconductor oampling gates at distances of (a) 33 , (b) 400 , anci (c) 1200 microns from the photoconductor fulbe generator

\section{REFERENCE}

11 D. H. Auston, "Impulso ropponse or" photocunduciora in transmisaton IInes," IEEE J quantum Eloctron., Vol, GE-19, op. 639-648, 1983. 